\title{
A New Nanoporous Material Based on Amorphous Silicon Dioxide
}

\author{
L. A. Vlasukova ${ }^{a}$, F. F. Komarov ${ }^{a}$, V. N. Yuvchenko ${ }^{a}$, O. V. Mil'chanin ${ }^{a}$, A. Yu. Didyk ${ }^{b}$, \\ V. A. Skuratov ${ }^{b}$, and S. B. Kislitsyn ${ }^{c}$ \\ ${ }^{a}$ Belarus State University, Minsk, 220030 Belarus \\ ${ }^{b}$ Joint Institute for Nuclear Research, Dubna, 141980 Russia \\ ${ }^{c}$ Institute of Nuclear Physics, National Nuclear Center, Almaty, 050032 Kazakhstan \\ e-mail:vlasukova@bsu.by
}

\begin{abstract}
Processes for making nanoporous $\mathrm{SiO}_{2}$ layers on $\mathrm{Si}$ via the irradiation of thermally oxidized silicon wafers with fast ions followed by chemical treatment in a solution or vapor of hydrofluoric acid are presented. It is shown that the density, shape, diameter, and length-to-diameter ratio of channels etched in silicon dioxide can be controlled by varying the regimes of fast ion irradiation or chemical treatment of $\mathrm{SiO}_{2} / \mathrm{Si}$ structures. Track parameters calculated using the thermal spike model are compared with the chemical etching data.
\end{abstract}

DOI: $10.3103 / \mathrm{S} 1062873812050267$

\section{INTRODUCTION}

As fast ions pass through solids, the high level of electron excitation results in the formation of latent tracks, extended cylinders 5 to $50 \mathrm{~nm}$ in diameter with altered density and deformed chemical bonds, embedded in the undamaged bulk. Using chemical etching, we can produce nanometer-sized channels in the regions of the tracks. This approach is used to make track membranes that are used as fine purification filters in organic synthesis, biotechnologies, and medicine from polymeric films. The etching of latent tracks can also be used for making channels in $\mathrm{SiO}_{2}$ layers on silicon [16]. Track etching is a threshold process. It is important to choose an irradiation regime that ensures track etching at each ion's point of incidence. A commonly used track "etchability" criterion is the electron energy lost from the ion upon entering the target, $(d E / d x)_{e}$. For $\mathrm{SiO}_{2}$, the threshold value $(d E / d x)_{e \text { thr }}$ varies, according to different data, from 4 to $1.5 \mathrm{keV} \mathrm{nm}^{-1}$ [7-10]. To ensure that we have layers with a high density of smalldiameter channels, however, it is important to know not only $(d E / d x)_{e \text { thr }}$ but also the other track parameters, e.g., the diameter of the track region that is formed as the ion passes through amorphous $\mathrm{SiO}_{2}$. The passage of fast ions through $\mathrm{SiO}_{2}$ and some other dielectrics is well described within the thermal spike model. Nanoporous $\mathrm{SiO}_{2}$ can be used as a template for making arrays of metallic and semiconductor nanoclusters and nanowires for nanoelectronic devices [12], active elements of biosensors [13, 14], and new-generation track membranes of higher thermal and chemical stability. Another possible field of application is the transport of ion beams in developing systems of new optics based on the interaction of guided beams of charged particles or quanta with the inner wall (walls) of a capillary [15].
This work presents the results from investigations aimed at the production of nanoporous $\mathrm{SiO}_{2}$ integrated into a $\mathrm{Si}$ wafer. It is shown that the calculated track parameters can be used as track etchability criteria.

\section{PROCEDURE}

Our simulations were performed within the thermal spike model [11] using a software package that we developed. The model assumes thermalization of the electron subsystem of a solid within a time no longer than $10^{-14} \mathrm{~s}$. In the next several picoseconds, the electron-phonon interaction leads to rapid heating of the region along the fast ion track. The process of energy transfer from the electron subsystem to the atomic subsystem of the solid is described by a system of two differential equations. Thermal fields are calculated using the macroscopic properties of the target material. The model involves one free parameter $\lambda$ : the mean electron path during electron-phonon interaction. If the density of the energy released in electron excitations is sufficiently high, the material is melted and a cylindrical region a few nanometers in diameter (a future track) is formed. In the next few tens of picoseconds, the melt is cooled to the temperature of the surrounding bulk. The thermal physics parameters of $\mathrm{SiO}_{2}$ needed for the calculations are taken from [11], and the parameter $\lambda$ is taken to be $4 \mathrm{~nm}$.

Silicon wafers oxidized in wet oxygen at $1000^{\circ} \mathrm{C}$ $\left(\mathrm{SiO}_{2} / \mathrm{Si}\right)$ with $\mathrm{SiO}_{2}$ layers 100 to $1200 \mathrm{~nm}$ thick were irradiated with normally incident ions having energies ranging from 40 to $710 \mathrm{MeV}$ in doses of $10^{8}$ to $5 \times$ $10^{10} \mathrm{~cm}^{-2}$, and were then treated in diluted solutions or vapors of hydrofluoric acid (HF). The thickness of the $\mathrm{SiO}_{2}$ layers was found from the Rutherford backscattering spectra or from an analysis of the cross sections of the $\mathrm{SiO}_{2} / \mathrm{Si}$ samples by means of transmission elec- 
Results from computer-aided simulation of track formation in $\mathrm{SiO}_{2}$

\begin{tabular}{l|c|c|c}
\hline $\begin{array}{c}\text { Type and energy } \\
\text { of ion, MeV }\end{array}$ & $\begin{array}{c}\text { Electron energy loss } \\
(d E / d x)_{e}, \mathrm{keV} \mathrm{nm}^{-1} \mathrm{SRIM}^{\prime} 2003\end{array}$ & $\begin{array}{c}\text { Melted region } \\
\text { radius } r, \mathrm{~nm}\end{array}$ & $\begin{array}{c}\text { Melted region } \\
\text { lifetime } t, \mathrm{ps}\end{array}$ \\
\hline $\operatorname{Ar}(290)$ & 2.8 & - & - \\
$\mathrm{Ar}(6.2)$ & 2.8 & $\begin{array}{c}\text { A region with } r=0.2 \mathrm{~nm} \\
\text { was heated to } T_{\text {melt }}\end{array}$ & - \\
$\mathrm{Kr}(253)$ & 9.8 & 3.4 & 7.0 \\
$\mathrm{Kr}(84)$ & 9.2 & 3.8 & 8.9 \\
$\mathrm{Fe}(56)$ & 6.9 & 2.7 & 3.9 \\
$\mathrm{~W}(180)$ & 15.8 & 6.3 & 24.4 \\
\hline
\end{tabular}

tron microscopy (TEM). The structure of the nanoporous layers was investigated with the aid of Hitachi S4800 and H-800 scanning and transmission electron microscopes.

\section{RESULTS AND DISCUSSION}

The table presents the $(d E / d x)_{e}$ values calculated using the SRIM' 2003 program and the results of the track formation simulation (the radius and the lifetime of the melted region produced in $\mathrm{SiO}_{2}$ as a fast ion passes through it). Upon irradiation with $290-\mathrm{MeVAr}$, $(d E / d x)_{e}=2.8 \mathrm{keV} \mathrm{nm}^{-1}$. This is higher than the threshold track etching values of $(d E / d x)_{e}$ given for amorphous $\mathrm{SiO}_{2}$ in $[9,10]$. However, we did not observe etched tracks in the samples irradiated with $\mathrm{Ar}$ $(290 \mathrm{MeV})$ even after treating them in $6 \% \mathrm{HF}$ for 20 min. Knowing $(d E / d x)_{e}$ alone is evidently not enough to predict formation of "etchable" tracks. As follows from the calculations (table) on the passage of $\operatorname{Ar}(290 \mathrm{MeV})$, there is no melting in $\mathrm{SiO}_{2}$. At the same time, upon the passage of much slower $\operatorname{Ar}(6.5 \mathrm{MeV})$ with the same $(d E / d x)_{e}$, a region with the radius of $0.2 \mathrm{~nm}$ is heated to the melting point. As can be seen, we must consider the "velocity effect" when evaluating the efficiency of track formation [16]. With fairly similar $(d E / d x)_{e}$, most of the energy released during the passage of a slower ion is localized in a narrow region along the track. During the passage of a faster ion, most of the energy is carried away by $\delta$ electrons quite far from the ion's trajectory. The slower ion thus causes greater heating of the substance in the region of the future track. In our calculations, this effect is demonstrated by $\mathrm{Kr}$ irradiation at 253 and $84 \mathrm{MeV}$. For $\mathrm{Kr}$ $(253 \mathrm{MeV}),(d E / d x)_{e}=9.8 \mathrm{keV} \mathrm{nm}^{-1}$, greater than for $84-\mathrm{MeV} \mathrm{Kr}\left(9.2 \mathrm{keV} \mathrm{nm}^{-1}\right)$. At the same time, the radius and lifetime of the melted region are larger for the slower $\mathrm{Kr}$ ion. It seems that the formation of the melted region along the ion trajectory is a more reliable track etchability criterion than the electron energy loss. Figure 1 shows etched tracks in $\mathrm{SiO}_{2} / \mathrm{Si}$ samples irradiated with $\mathrm{Fe}(56 \mathrm{MeV}), \mathrm{Kr}(84 \mathrm{MeV})$, and $\mathrm{W}(180 \mathrm{MeV})$ ions and treated by $1.5 \% \mathrm{HF}$ for nine minutes. The diameter of pores in $\mathrm{SiO}_{2}$ irradiated with $\mathrm{Fe}$ ions was $\approx 15 \mathrm{~nm}$. In the samples irradiated with $\mathrm{Kr}$ and $\mathrm{W}$, the pore diameters were 30 and $45 \mathrm{~nm}$, respectively. Thus, under identical etching conditions pores with the smallest diameter were formed in $\mathrm{SiO}_{2}$ irradiated with ions which, according to our calculations, produced melted regions with a short radius and lifetime. The etched tracks had the greatest diameter in the case of irradiation with $\mathrm{W}$ ions, which produced the melted region with the greatest radius and lifetime (see table).

Irradiation with high doses of fast ions $(1-5) \times$ $10^{10} \mathrm{~cm}^{-2}$ results in the formation of a $\mathrm{SiO}_{2}$ layer with a high density of overlapping capillaries that feature an irregular shape and a well-developed surface (Fig. 2). Lowering the dose to $\leq 10^{9} \mathrm{~cm}^{-2}$ allows a system of isolated channels of virtually identical size and regular conical shape to be produced in dielectrics (Fig. 3). The conic shape of pores is due to the track etching rate $V_{\mathrm{t}}$ and the undamaged bulk etching rate $V_{\mathrm{b}}$ being comparable in value. Knowing etching time $t_{e}$, pore depth $z$, and pore cone half-angle $\beta$, we can calculate $V_{\mathrm{t}}$ and $V_{\mathrm{b}}$ from the relations $z=\left(V_{\mathrm{t}}-V_{\mathrm{b}}\right) t_{e}$ and $\sin \beta=$ $V_{\mathrm{b}} / V_{\mathrm{t}}$ [17]. These calculations were performed for $\mathrm{Bi}$ irradiated samples with an energy of $710 \mathrm{MeV}$ and treated in $1.2 \%$ HF. The values of $V_{\mathrm{t}}$ and $V_{\mathrm{b}}$ averaged over the results of eight measurements were 22.7 and $5.8 \mathrm{~nm} \mathrm{~min}{ }^{-1}$, respectively. They were close to the values reported in [2,3] for tracks in $\mathrm{SiO}_{2}$ etched in $1 \% \mathrm{HF}$. We showed earlier [6] that, with all irradiation and chemical treatment conditions being equal, the diameter of etched tracks increases linearly with the time of etching in HF solution. This, along with knowledge of $V_{\mathrm{t}}$ and $V_{\mathrm{b}}$, allows us to predict the regimes of chemical treatment in $\mathrm{HF}$ solutions for making porous $\mathrm{SiO}_{2}$ layers of required thickness with through channels of a given diameter. Through channels filled with tin dioxide in the $\mathrm{SiO}_{2}$ layer are shown in Fig. 4. The channels are characterized by a regular shape, identical size, and smooth inner walls. The formation of through channels is a necessary condition for electrical contact with the conducting wafer, the formation of nanowires or nanoclusters in the channels by electrochemical methods, and for constructing passive and active ele- 

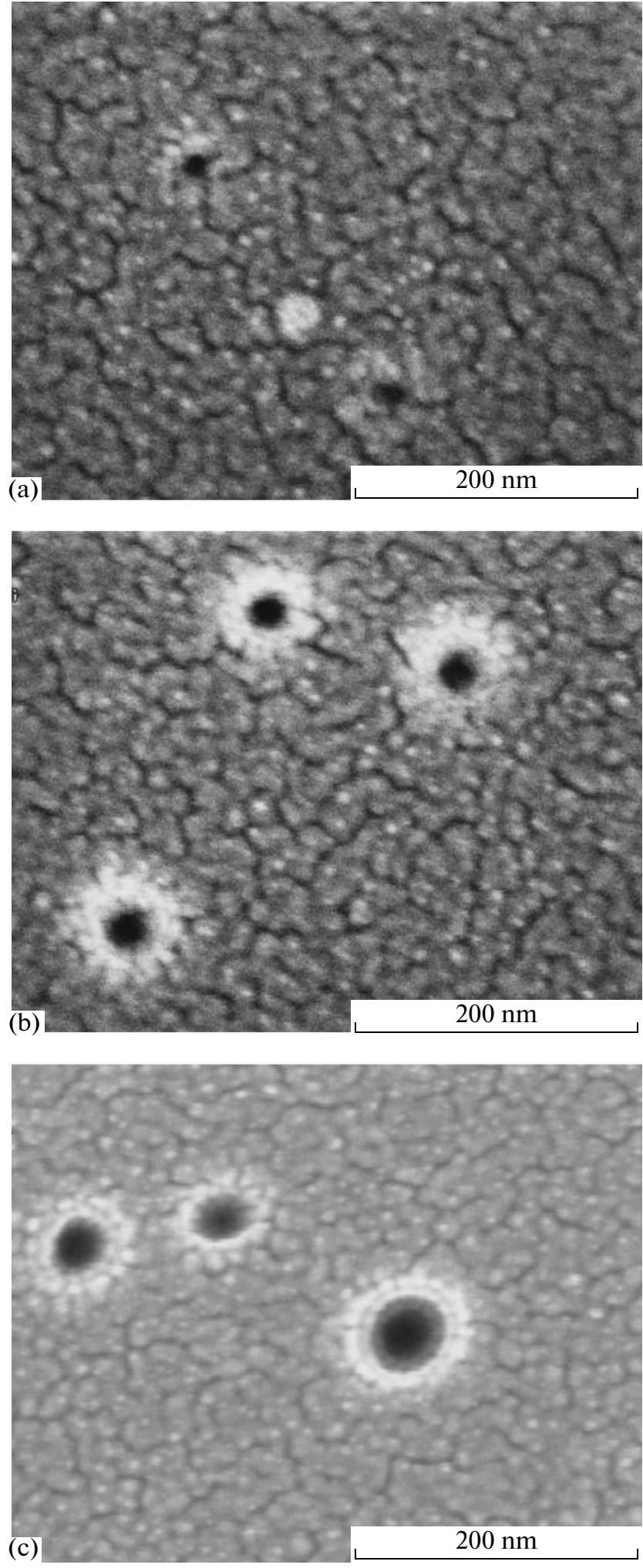

Fig. 1. Tracks etched in $\mathrm{SiO}_{2}$, after treatment with $1.5 \% \mathrm{HF}$ for 9 min. (a) Irradiation with Fe $\left(56 \mathrm{MeV}, 2-4 \times 10^{8} \mathrm{~cm}^{-2}\right)$; (b) irradiation with $\mathrm{Kr}\left(84 \mathrm{MeV}, 2-4 \times 10^{8} \mathrm{~cm}^{-2}\right)$; (c) irradiation with $\mathrm{W}\left(180 \mathrm{MeV}, 3 \times 10^{8} \mathrm{~cm}^{-2}\right)$. The inhomogeneity of the background is due to the texture of the gold layer deposited on the samples to remove the static charge caused by electron beam scanning in the microscope chamber.
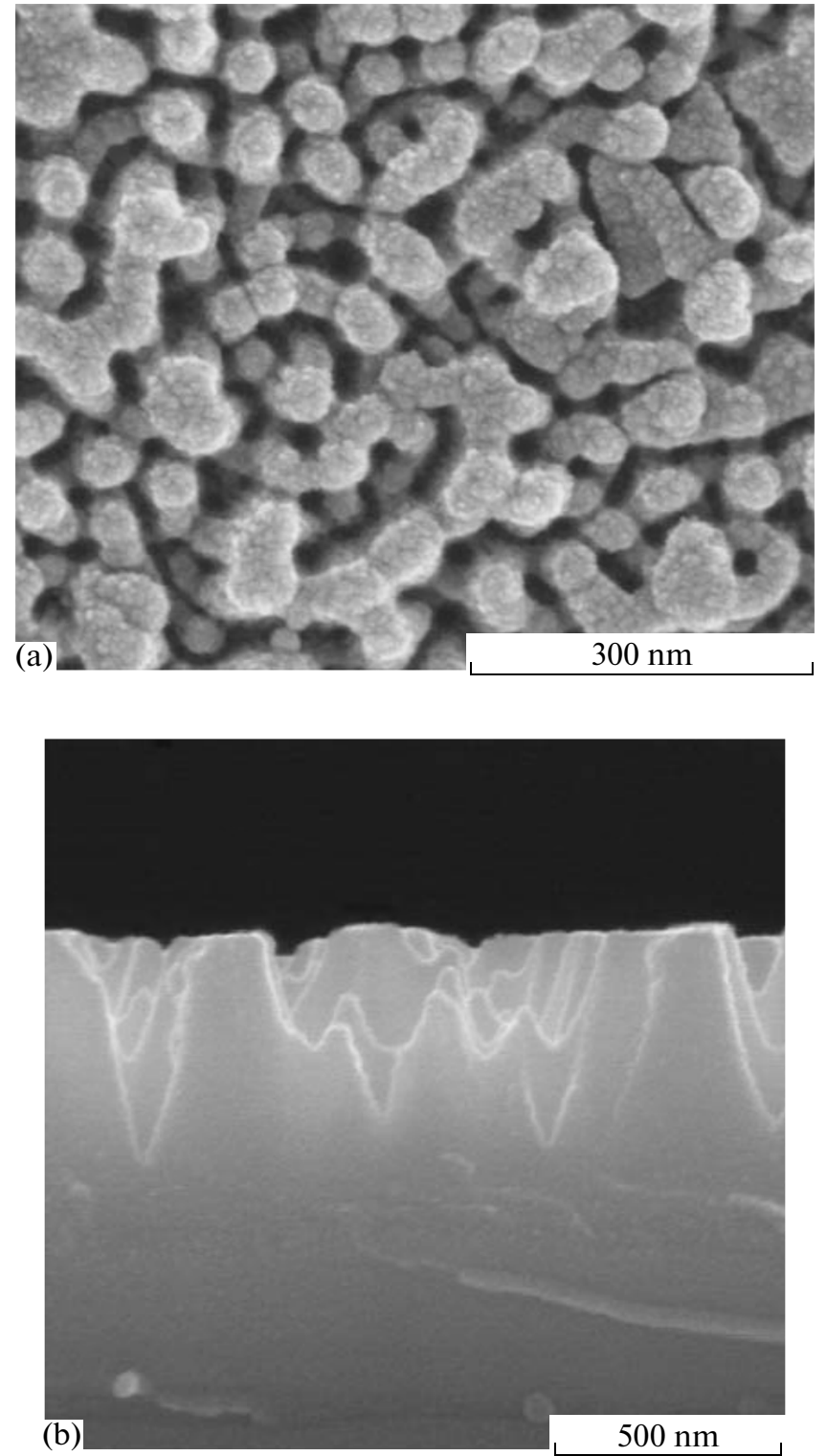

Fig. 2. Surface (a) and cross section (b) of a $\mathrm{SiO}_{2} / \mathrm{Sii}$ sample irradiated with $\mathrm{Bi}\left(710 \mathrm{MeV}, 5 \times 10^{10} \mathrm{~cm}^{-2}\right)$ after treatment with $1.2 \% \mathrm{HF}$ for $20 \mathrm{~min}: N_{\text {pore }} \approx 10^{10} \mathrm{~cm}^{-2}$.

ments of track electronics based on etched ion tracks filled with the appropriate materials [12].

When choosing the irradiation regime, we must consider the effect of track overlapping at high ions doses. Ideally, the track is a cylinder of damaged material around the ion trajectory, the diameter of which is governed by the type of irradiated material and the density of energy released during ion deceleration. For a random distribution of tracks, the average distance between neighboring tracks is $\langle a\rangle=1 / 2 \sqrt{ } n$, where $n$ is the average density of tracks [18]. Provided that each ion incident on the surface of amorphous $\mathrm{SiO}_{2}$ forms an etchable track, the track density is equal to the irradiation dose. For the dose of $5 \times 10^{10} \mathrm{~cm}^{-2},\langle a\rangle \approx 22 \mathrm{~nm}$. 

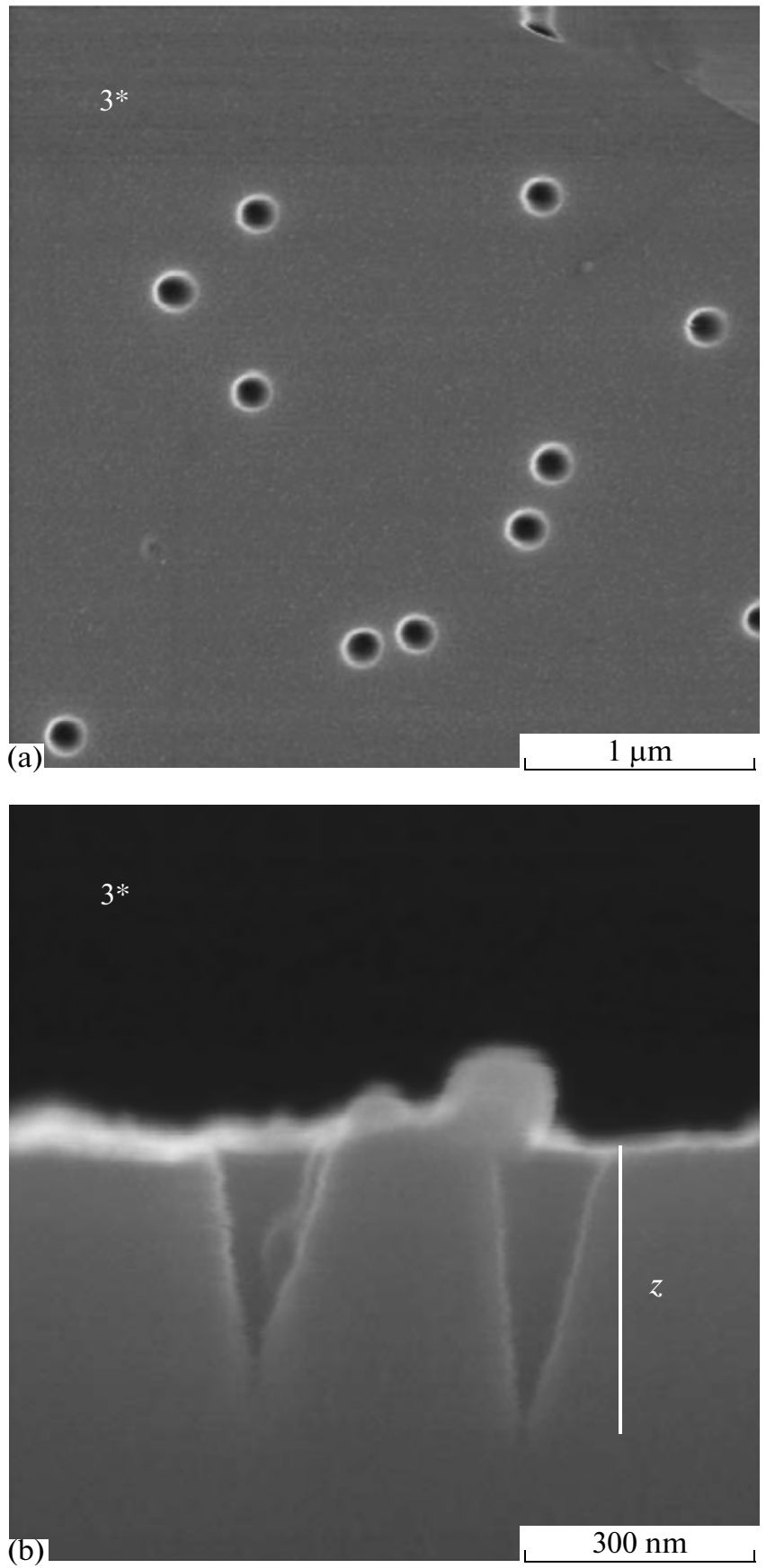

Fig. 3. Surface (a) and cross section (b) of $\mathrm{a} \mathrm{SiO}_{2} / \mathrm{Si} \mathrm{sam-}$ ple irradiated with $\mathrm{Bi}\left(710 \mathrm{MeV}, 1-3 \times 10^{8} \mathrm{~cm}^{-2}\right)$ after treatment with $1.2 \% \mathrm{HF}$ for $20 \mathrm{~min}: N_{\text {pore }} \approx 2.3 \times 10^{8} \mathrm{~cm}^{-2}$; diameter $\approx 140 \mathrm{~nm}$.

As was shown earlier [6], according to the data of etching after irradiation with $\mathrm{Bi}(710 \mathrm{MeV})$ ions, track core diameter $D_{0}$ is $20 \mathrm{~nm}$. Thus, for a bismuth dose of $5 \times 10^{10} \mathrm{~cm}^{-2},\langle a\rangle \approx D_{0}$. Investigations of polymers, alkali halide crystals, and semiconductors $\mathrm{A}^{3} \mathrm{~B}^{5}$ have shown that ion tracks in solids consist of narrow cores surrounded by defective halos [19-22]. Since
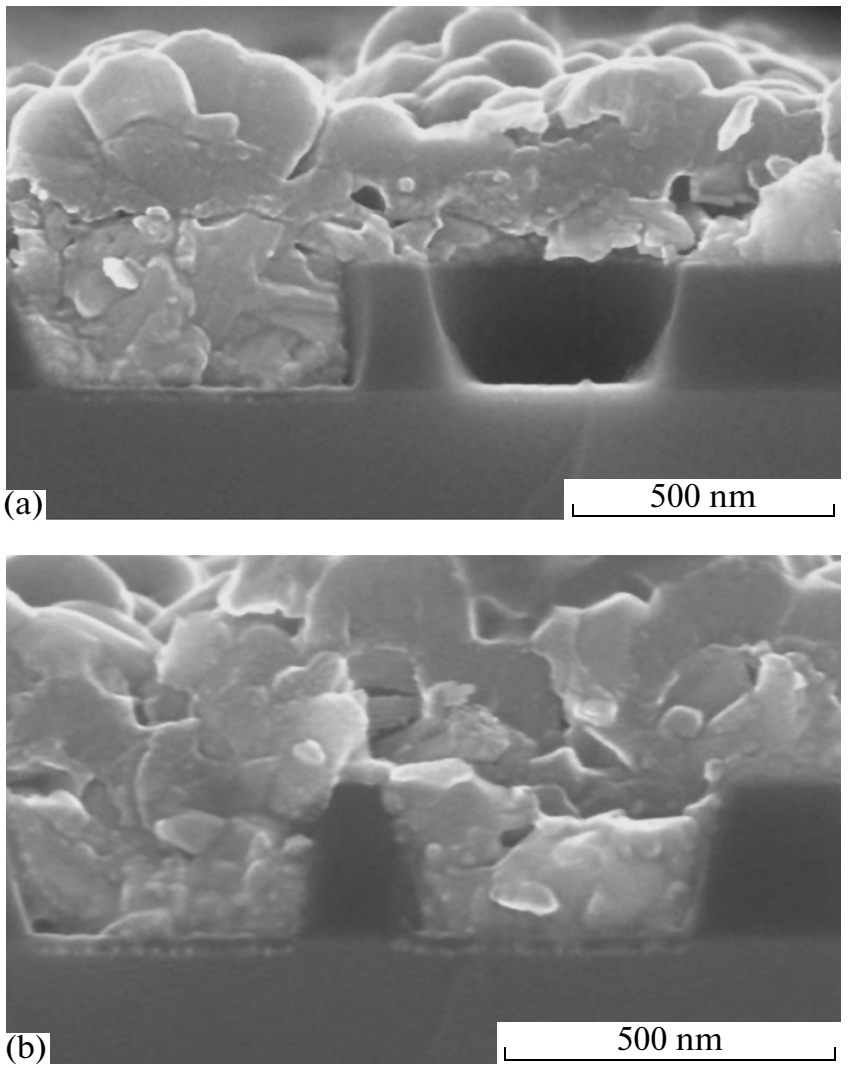

Fig. 4. Cross sections of a $\mathrm{SiO}_{2} / \mathrm{Si}$ sample irradiated with $\mathrm{Xe}\left(130 \mathrm{MeV}, 10^{8} \mathrm{~cm}^{-2}\right)$ after treatment with $1.5 \% \mathrm{HF}$ for $50 \mathrm{~min}$. The thickness of the porous layer is $220 \mathrm{~nm}$; the diameter of the pores near the surface is $450 \mathrm{~nm}$. Pores are filled with tin dioxide.

the halos are highly defective, the etching rate in the region of a halo should be higher than the undamaged bulk etching rate. In the case of $\mathrm{Bi}(710 \mathrm{MeV})$ with a track density of $5 \times 10^{10} \mathrm{~cm}^{-2}$, neighboring tracks will affect each other because of halo overlapping and partial track core overlapping (see Fig. 2). With a track density of $2.3 \times 10^{8} \mathrm{~cm}^{-2},\langle a\rangle \approx 330 \mathrm{~nm}$. this is appreciably less than $D_{0}$. Consequently, the regular conical shape, virtually identical size, and pore density corresponding to the dose of irradiation in samples irradiated with a low Bi dose indicate there is no track overlapping (see Fig. 3). To eliminate the track overlapping effect, it is important to evaluate the minimum diameter of the pore that can be etched at the track's location after irradiation with a particular type of ion with a given energy. In this case, the track core diameter can be taken as the minimum pore diameter. As was mentioned above, the track core diameter for $\mathrm{Bi}(710 \mathrm{MeV})$ is $20 \mathrm{~nm}$. The calculated diameter of the melted region formed in $\mathrm{SiO}_{2}$ upon the passage of $\mathrm{Bi}(710 \mathrm{MeV})$ is $15.2 \mathrm{~nm}$. The good correlation between the diameters of the track core and the calculated melted region allows the minimum diameter of the etched tracks to be predicted. If slower ions are used for irradiation, $D_{0}$ 

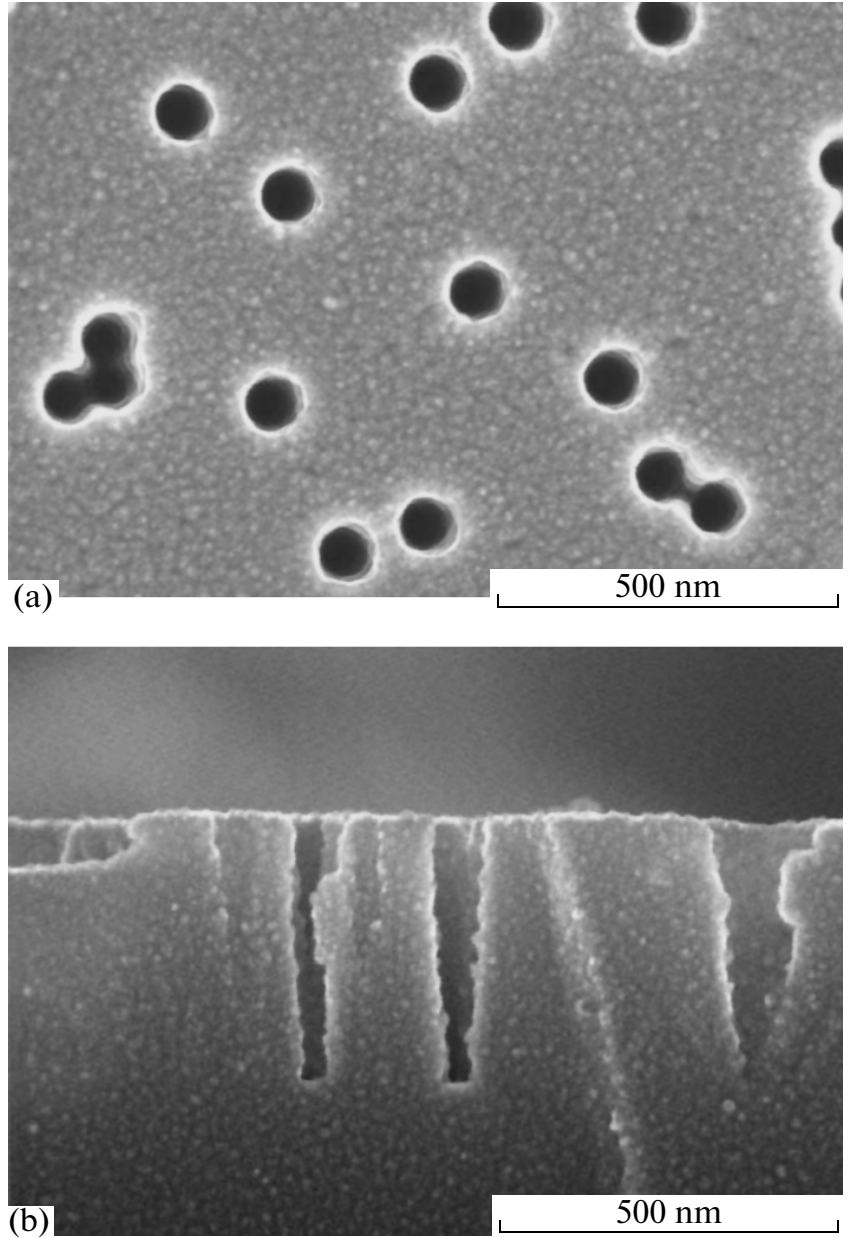

Fig. 5. Surface (a) and cross section (b) of a $\mathrm{SiO}_{2} / \mathrm{Si}$ sample irradiated with $\mathrm{Bi}\left(710 \mathrm{MeV}, 1-2 \times 10^{9} \mathrm{~cm}^{-2}\right)$ after treatment with HF vapor for $45 \mathrm{~min}: N_{\text {pore }} \approx 1.5 \times 10^{9} \mathrm{~cm}^{-2}$; diameter $\approx 60 \mathrm{~nm}$; length-to-diameter ratio $\approx 12-15$.

can be reduced to $\approx 5 \mathrm{~nm}$. This would allow us to increase the upper limit for the dose of irradiation without track overlapping to $\approx 10^{11} \mathrm{~cm}^{-2}$.

For some applications, it would be interesting to produce $\mathrm{SiO}_{2}$ layers with cylindrical channels [1]. Treatment of $\mathrm{SiO}_{2} / \mathrm{Si}$ samples in $\mathrm{HF}$ vapor could allow predominant etching of $\mathrm{SiO}_{2}$ in the track region while the bulk etching rate remains very low. This results in almost cylindrical channels with a very high length-todiameter ratio (Fig. 5). Compared to liquid etching, however, the roughness of the surface and the inner walls of the pores is noticeably higher. For the sample irradiated with $\mathrm{Bi}\left(710 \mathrm{MeV}, 2 \times 10^{9} \mathrm{~cm}^{-2}\right)$, the bulk etching rate was $V_{\mathrm{b}} \approx 3.1 \mathrm{~nm} \mathrm{~min}{ }^{-1}$, which is appreciably lower than the etching rate in HF solutions. When the pore diameter reaches the value $\approx 60 \mathrm{~nm}$, it stops increasing as the time of etching in $\mathrm{HF}$ vapor increases.

Information on the thermal stability of latent tracks in $\mathrm{SiO}_{2}$ was obtained from our TEM analysis of planview samples. Since the planview samples were thinned by

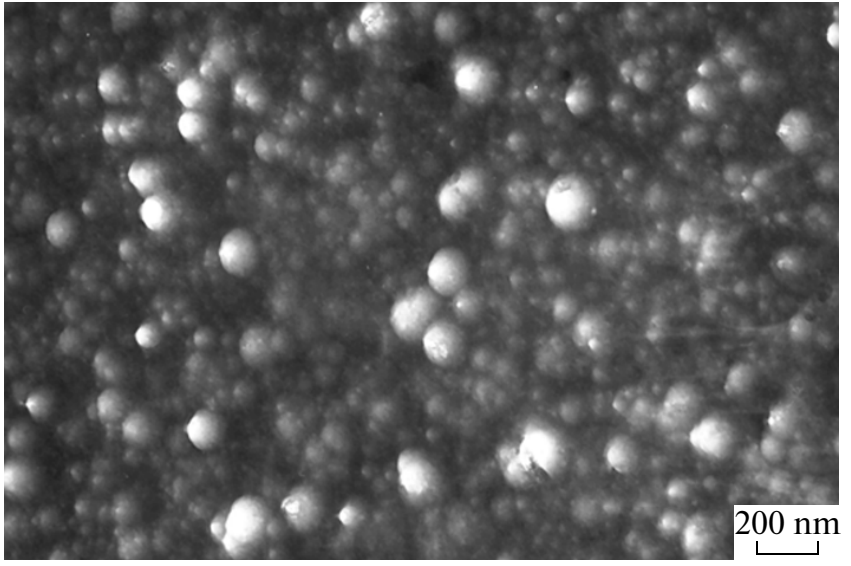

Fig. 6. Planview image of the $\mathrm{SiO}_{2}$ layer irradiated with $\mathrm{Au}$ $\left(593 \mathrm{MeV}, 10^{13} \mathrm{~cm}^{-2}\right)$, as seen in the transmission electron microscope.

chemical etching in a concentrated $\mathrm{HF}: \mathrm{HNO}_{3}=1: 5$ acid mixture, the existence of strongly damaged regions in the bulk (latent tracks) resulted in their predominant etching during the thinning process. In microphotographs, they appear as rounded light-contrast regions (Fig. 6). Our planview patterns did not change after thermal treatment of the irradiated samples at $900^{\circ} \mathrm{C}$ for 30 minutes, indicating the thermal stability of defects induced by fast ions in silicon dioxide. Similarly, no changes were observed in the morphology of the already etched tracks after thermal treatment at $900^{\circ} \mathrm{C}$ for 30 minutes (not shown in the figure).

\section{CONCLUSIONS}

We investigated the morphology of etched tracks in layers of amorphous $\mathrm{SiO}_{2}$ on $\mathrm{Si}$. We showed that due to the track overlapping effect, irradiation with high doses of fast ions $\left(1-5 \times 10^{10} \mathrm{~cm}^{-2}\right)$ results in the formation of a $\mathrm{SiO}_{2}$ layer with capillaries of irregular shape and a highly developed surface. Doses $\leq 10^{9} \mathrm{~cm}^{-2}$ allow us to produce a system of channels of virtually identical size and regular shape.

Treatment of irradiated samples in HF-based solutions results in the formation of cone-shaped channels; etching in HF vapor allows nanometer-sized channels of almost cylindrical shape with a length-todiameter ratio of $\approx 12-15$ to be formed in $\mathrm{SiO}_{2}$.

Track parameters in $\mathrm{SiO}_{2}$ calculated within the thermal spike model are compared with the results of chemical track etching. It is shown that existence of a melted region along the ion trajectory can serve as an etchability criterion for tracks in $\mathrm{SiO}_{2}$. With all other chemical treatment conditions being the same, the diameter of the etched tracks increases with increasing calculated diameter and lifetime of the melted region. This information can be used to choose the irradiation 
regime for producing $\mathrm{SiO}_{2}$ layers with high pore density (above $5 \times 10^{10} \mathrm{~cm}^{-2}$ ).

The thermal stability of ion tracks in amorphous $\mathrm{SiO}_{2}$ and the thermal stability of the system of pores produced by track etching in $\mathrm{SiO}_{2}$ were evaluated. It was shown that defects in the regions of ion tracks were not annealed after 30 minutes of thermal treatment at $900^{\circ} \mathrm{C}$. Similarly, no changes were observed in the morphology of porous $\mathrm{SiO}_{2}$ after 30 minutes of thermal treatment at $900^{\circ} \mathrm{C}$.

\section{REFERENCES}

1. Musket, R.G., Yoshiyama, J.M., and Contolini, J., Appl. Phys., 2002, vol. 91, p. 5760.

2. Milanez Silva, C., Varisco, P., Moehlecke, A., et al., Nucl. Instrum. Methods B, 2003, vol. 206, p. 486.

3. Canut, B., Blanchin, M.G., Ramos-Canut, S., et al., Nucl. Instrum. Methods B, 2006, vol. 245, p. 327.

4. Komarov, F.F., Vlasukova, L.A., Yuvchenko, V.N., Didyk, A.Yu., and Skuratov, V.A., Bull. Russ. Acad. Sci. Phys., 2006, vol. 70, no. 6, p. 910.

5. Bergamini, F., Bianconi, M., Cristiani, S., et al., Nucl. Instrum. Methods B, 2008,vol. 266, p. 2475.

6. Komarov, F.F., Vlasukova, L.A., Kuchinskyi, P.V., et al., Lithuanian J. Phys., 2009, vol. 49, p. 111.

7. Nuclear Tracks in Solids, Fleischer, R.L., Ed., Berkeley: Univ. California Press, 1975.

8. Sigrist, A. and Balzer, R., Helv. Phys. Acta, 1977, vol. 50 , p. 75 .
9. Jensen, J., Skupinski, M., Razpet, A., and Possnert, G., Nucl. Instrum. Methods B, 2006, vol. 245, p. 269.

10. Dallanora, A., Marcondes, T.L., Bermudez, G.G., et al., J. Appl. Phys., 2008, vol. 104, p. 024307(8).

11. Toulemonde, M., Dufour, C., Meftah, A., et al., Nucl. Instrum. Methods B, 2000, vol. 166/167, p. 903.

12. Hoppe, K., Fahrner, W.R., Fink, D., et al., Nucl. Instrum. Methods B, 2008, vol. 266, p. 1642.

13. Fujimaki, M., Rockstuhl, C., Wang, X., et al., Opt. Exp., 2008, vol. 16, p. 6408.

14. Fertig, N., Blick, R. H., and Berhends, J.C., Biophys. J., 2002, vol. 18, p. 3056.

15. Stolterfoht, N., Hellhammer, R., Juhász, Z., et al., Phys. Rev. A, 2010, vol. 82, p. 052902.

16. Meftah, A., Brisard, F., Costantini, J.M., et al., Phys. Rev. B, 1994, vol. 49, p. 12457.

17. Spohr, R., Ion Tracks and Microtechnology: Principles and Applications, Wisbaden: Viweg Verlag, 1990.

18. Apel, P.Yu., Blonskaya, I.V., Dmitriev, S.N., et al., J. Membrane Sci., 2006, vol. 282, p. 393.

19. Apel, P.Yu., Akimenko, A.P, Blonskaya, I.V., et al., Nucl. Instrum. Methods B, 2006, vol. 245, p. 284.

20. Trautmann, C., Schwartz, K., and Steckenreiter, T., Nucl. Instrum. Methods B, 1999, vol. 156, p. 162.

21. Hida, A., Iwase, A., Mera, Y., et al., Nucl. Instrum. Methods B, 2003, vol. 209, p. 140.

22. Komarov, F.F., Vlasukova, L.A., Yuvchenko, V.N., et al., Vacuum, 2005, vol. 78, pp. 353-359. 